\title{
Ichneumonidae (Insecta: Hymenoptera) in Canadian Late Cretaceous amber
}

\author{
Ryan C. McKellar*,1,2, Dmitry S. Kopylov ${ }^{3}$ and Michael S. Engel ${ }^{1}$ \\ ${ }^{1}$ Division of Entomology (Paleoentomology), Natural History Museum, and Department of Ecology \& Evolutionary Biology, \\ 1501 Crestline Drive - Suite 140, University of Kansas, Lawrence, KS 66045, USA, R. C. McKellar, \\ E-mail: rcm1@ualberta.ca, M. S. Engel, E-mail: msengel@ku.edu \\ 2 Department of Earth \& Atmospheric Sciences, 1-26 Earth Sciences Building, University of Alberta, Edmonton, Alberta T6G 2E3, Canada \\ ${ }^{3}$ Borissiak Paleontological Institute, Russian Academy of Sciences, Profsoyuznaya ul. 123, Moscow, 117997, Russia. \\ E-mail: aeschna@yandex.ru
}

Received 22 November 2012

Accepted 17 December 2012

Published 5 August 2013

\section{Key Words}

\section{Campanian}

fossil Hymenoptera

Grassy Lake amber

Labeninae

Labenopimplinae

\begin{abstract}
Three new species and two new genera are described within the wasp family Ichneumonidae from Late Cretaceous (Campanian) amber collected at the Grassy Lake locality in Alberta, Canada. New taxa include Pareubaeus rasnitsyni n. gen. et sp. and $P$. incertus n. sp. within the subfamily Labenopimplinae, and Albertocryptus dossenus $\mathrm{n}$. gen. et sp. within the subfamily Labeninae. The presence of a labenopimpline genus closely related to Eubaeus Townes within Canadian amber further supports faunal similarity between the Canadian assemblage and that recovered from Siberian amber. The records of Labeninae are the first from Mesozoic amber, and demonstrate that the subfamily was present in the Northern Hemisphere in the Late Cretaceous, as opposed to their modern, predominantly austral distribution.
\end{abstract}

\section{Introduction}

With an estimated diversity of approximately 60,000 species, and more than 23,300 described species, ichneumonids are one of the most diverse hymenopteran families in many modern ecosystems (Gauld \& Bolton 1988; Wahl \& Sharkey 1993; Yu et al. 2005; Huber 2009; Engel \& Krombein 2012). Despite their prominent role in modern ecosystems, the Ichneumonidae have a relatively sparse fossil record in the Mesozoic. Most of our knowledge of Mesozoic ichneumonids stems from compression fossils (summarized in Kopylov 2010a), because they are seldom encountered in amber. To date, only nine specimens of Ichneumonidae have been described from Siberian amber (i.e., the Cenomanian Agapa, Late Cretaceous Baikura, and Santonian Yantardakh localities on the Taimyr Peninsula: Townes 1973a, 1973b; Kopylov 2012). There have been no reports of Ichneumonidae from major Early Cretacous deposits including Charentes amber from France (Albian-Cenomanian: Perrichot et al. 2010), Spanish amber (Albian: Peñalver \& Delclòs 2010), or Lebanese amber (Aptian: Azar et al. 2010). Late Cretaceous (Turonian) New Jersey amber has been reported to contain four specimens of Ichneumonidae, but these remain undescribed (Grimaldi et al. 2000), and a single specimen of an undescribed species has been figured from Early Cretaceous Burmese amber (from Myanmar, Cenomanian/Turonian in age: Ross et al. 2010). There have also been previous reports of ichneumonids within Campanian Canadian amber (Pike 1995; Skidmore 1999; McKellar et al. 2008; McKellar \& Engel 2012), but the specimens have remained undescribed until now.

It appears as though the main reason that ichneumonids are poorly represented as fossils in the Cretaceous is their body size. Those forms that are represented are typically less than $2.8 \mathrm{~mm}$ in total body length, placing them within the smallest size class known for modern or even Tertiary taxa (Kopylov 2012, and references therein). Amber provides an ideal medium for preserving such small insects, but there is also some risk that the amber record is biased toward preserving smaller forms, because larger taxa are able to free themselves from the entrapping resin, or are not fully encapsulated

\footnotetext{
* Corresponding author
} 
and therefore not preserved (Martínez-Delclòs et al. 2004; McKellar \& Engel 2012). This said, the compression fossil record of Cretaceous ichneumonids also displays a remarkably high percentage of small forms, suggesting that small forms may simply have been more abundant in the Cretaceous (Kopylov 2012), and by extension, that amber may provide a relatively unbiased record in this time period.

\section{Materials and methods}

Specimens were prepared using established techniques for the preparation of fragile amber specimens (Nascimbene \& Silverstein 2000), and the resulting epoxy-embedded amber pieces were slide mounted and polished to obtain thin sections. Observations were made using an Olympus SZX12 stereomicroscope, and an Olympus BX51 compound microscope. Photomicrographs were prepared using a Cannon EOS 7D camera attached to an Infinity K-2 long-distance microscope with Xenon-flash lighting, and a Zeiss Axio Imager A1 was utilized for dark field compound microscopy. Serial photography and Helicon Focus software were used to improve focal depth in the images presented. Terminology follows that of Townes (1969) and is supplemented with some generalized hymenopteran terminology from Huber \& Sharkey (1993); vein nomenclature is presented in Figure 4A.

Institutional abbreviations used herein are: TMP, Royal Tyrrell Museum of Palaeontology, Drumheller, Alberta, Canada; P, Department of Earth and Atmospheric Sciences Palaeontology Museum, University of Alberta, Edmonton, Alberta, Canada.

\section{Systematic palaeontology}

\section{Family Ichneumonidae Latreille, 1802}

\section{Subfamily Labenopimplinae Kopylov, 2010b}

Remarks. Labenopimplinae is a recently erected subfamily composed exclusively of Late Cretaceous fossil ichneumonids with characteristics intermediate between the modern subfamilies Labeninae and Pimplinae, as well as some characters found in Tryphoninae (Kopylov 2010b, 2012; Kopylov et al. 2010). Monophyly of the subfamily has yet to be explicitly tested and it may be paraphyletic with respect to some modern lineages.

Composition. Agapia Kopylov, 2012; Agapteron, Kopylov, 2012; Armanopimpla Kopylov, 2010b; Catachora Townes, 1973b; Eubaeus Townes, 1973b; Labenopimpla Kopylov, 2010b; Micropimpla Kopylov, 2010b; Pareubaeus n. gen.; Ramulimonstrum Kopylov, 2010b; Rugopimpla Kopylov, 2010b; Urotryphon Townes, 1973b. Late Cretaceous of Asia, Africa, and North America.

\section{Genus Pareubaeus McKellar, Kopylov \& Engel, n. gen.}

Derivation of name. The genus name is a combination of para, the Greek for "near", and Eubaeus, the genus established by Townes (1973b). It is masculine.

Type species. Pareubaeus rasnitsyni n. sp.

Diagnosis. Antennae with 11 flagellar articles, completely filiform or with last article club-shaped. Notauli apparently parallel and weakly impressed. Protibia with one curved spur, meso- and metatibiae with pair of straight spurs; pretarsal claws smooth. Forewing with rs-m ab- sent, but with $\mathrm{M}$ present and bent at both rs-m contact and $2 \mathrm{~m}-\mathrm{cu}$ contact; r-rs contacting Rs $+\mathrm{M}$ slightly before its branching, forming a short abscissa $3 \mathrm{Rs}+\mathrm{M}$; 1m-cu\&2Rs $+\mathrm{M}$ smooth, without any traces of ramulus $(1 \mathrm{Rs}+\mathrm{M}) ; 2 \mathrm{~m}$-cu completely spectral; $1 \mathrm{cu}-\mathrm{a}$ postfurcal. Hind wing with four hook-shaped distal hamuli; 1Rs very short; 2Rs short; $2 \mathrm{M}$ absent. Metasoma slender. Forewing length of known species 1.08-1.28 mm. Pareubaeus shows high degree of similarity to Eubaeus Townes, 1973b, from which it differs in possession of forewing with $2 \mathrm{~m}$-cu cross-vein and vein $\mathrm{M}$ bent just apical to foreshortened rs-m. New genus differs from all other genera within subfamily, possessing antennae with 11 flagellar articles and slightly reduced forewing venation: rs-m reduced, $2 \mathrm{~m}$-cu spectral, r-rs contacting $\mathrm{Rs}+\mathrm{M}$ before its branching.

Species composition. Pareubaeus rasnitsyni n. sp., P. incertus n. sp., both from Late Cretaceous (Campanian) amber of western Canada.

\section{Pareubaeus rasnitsyni McKellar, Kopylov \& Engel, \\ n. sp.}

Figures $1 \mathrm{~A}-\mathrm{C}, 2 \mathrm{~A}$

Derivation of name. The specific epithet is a patronym in honor of Alexandr P. Rasnitsyn, recognizing his massive contribution to the understanding of fossil Hymenoptera.

Holotype. TMP 96.9.192a (trailing specimen within amber piece), imago, male. Wings, legs, and antennae well preserved; sculpture of head and mesosoma unclear due to thin-cuticle deformation; genitalia not preserved. Grassy Lake amber, Foremost Formation, Campanian.

Diagnosis. Antennal length equal to 0.74 of total body length; flagellar articles progressively shortening and (slightly) widening from base to apex; lengths range from article II, 0.9 times as long as article I, to article X, 0.68 times as long as article I; flagellar article XI distinctive, club-shaped, 0.93 times length of first article, and widest, approximately 1.5 times width of article X. Mesopleuron comparatively short, 0.31 of mesosomatic length. Forewing with straight anterior margin on pterostigma; $2 \mathrm{Rs}+\mathrm{M}$ bulla displaced basal from r-rs contact; $1 \mathrm{Rs} \& 1 \mathrm{M}$ bowed, concave apically; $4 \mathrm{Cu}$ deflected posteriorly just apical to 2cu-a. Metasoma fusiform, with 1st segment long and thin, 4th and 5th segments widest.

Description. Head nearly hemispherical; compound eyes large, positioned anterolaterally, and apparently glabrous; ocelli positioned anteriorly, near anterior margin of compound eyes; antennae borne high on head, on moderate frontal prominence with dorsoventral row of at least six moderately long, erect setae (Fig. 1C); scape relatively short, nearly cylindrical, and slightly wider than basal flagellar articles; pedicel swollen to twice width of basal flagellar articles near its mid-

Figure 1. Pareubaeus rasnitsyni $\mathrm{n}$. gen. et $\mathrm{sp}$. and P. incertus $\mathrm{n}$. gen. et sp. from Late Cretaceous Grassy Lake amber, Alberta, Canada. A-C. P. rasnitsyni, holotype male, TMP 96.9.192a (trailing specimen); A. Oblique ventral view; B. Oblique dorsal view; C. Details of setae on head, antennae, and mesosoma (dark field photomicrographs); D-H. P. incertus, holotype male, TMP 96.9.192 b (leading specimen); D. Oblique lateral view (left); E. Oblique lateral view (right); F. Protarsus and protibial spur; G. Meso- and metatibial spurs and meso(upper) and metatarsi (lower); H. Partially exposed male genitalia; I. Probable conspecific male with undistorted preservation of head and body, but poorly preserved wings (wings are not preserved apical to pterostigma), TMP 96.9.787. Scale bars $0.5 \mathrm{~mm}$ (A, B, D, I), $0.1 \mathrm{~mm}$ (C), $0.05 \mathrm{~mm}$ (F, G, H). 

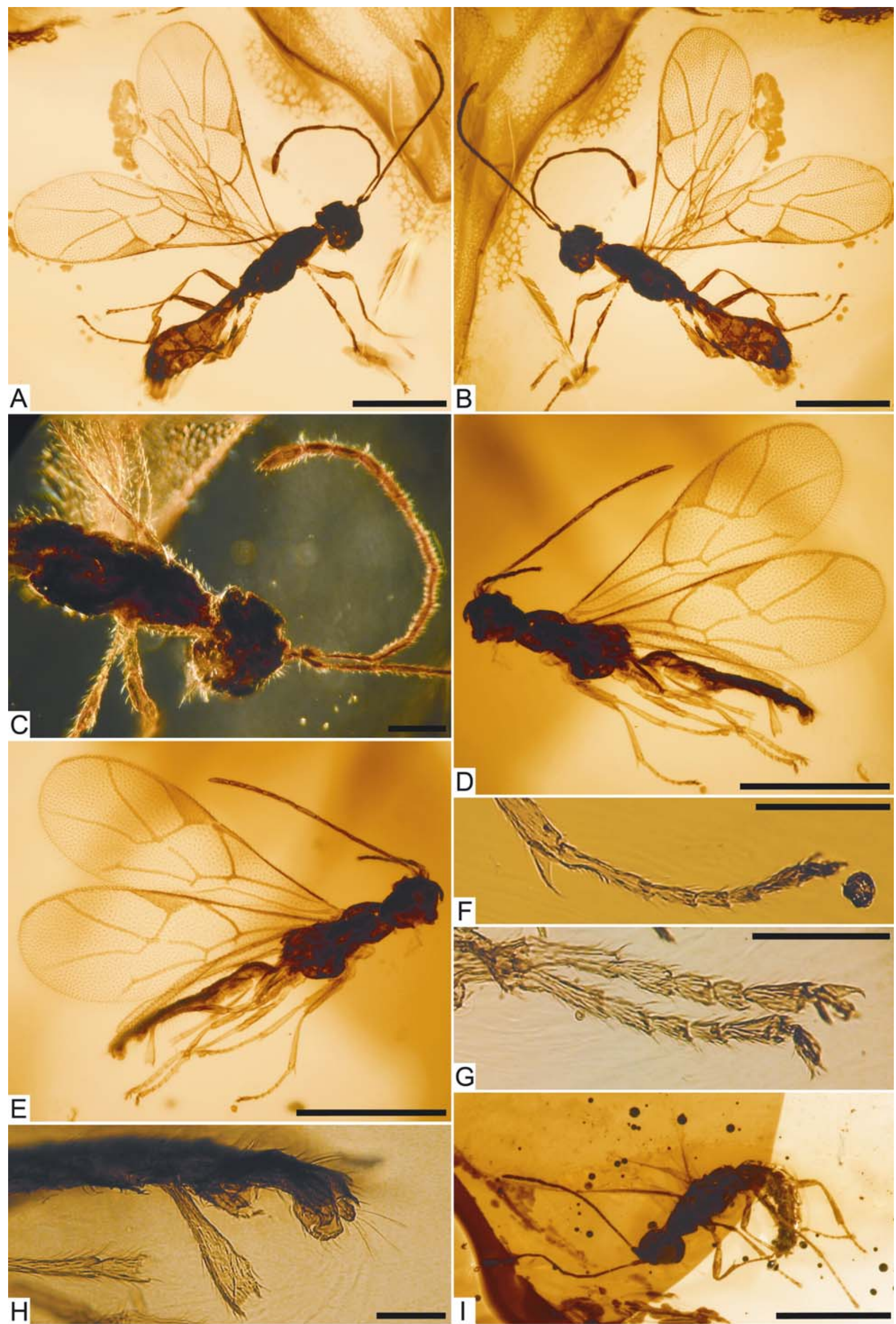


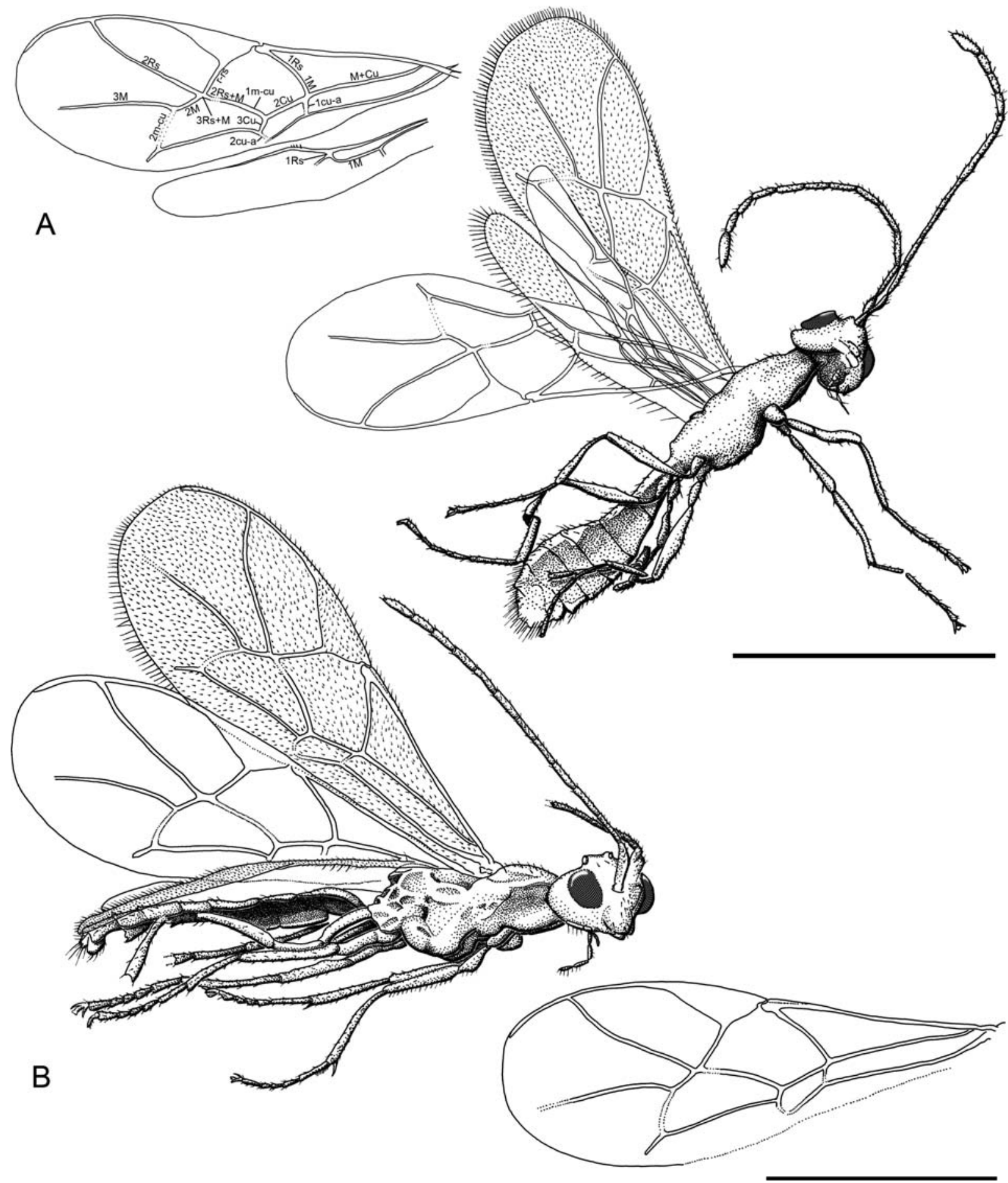

Figure 2. Pareubaeus rasnitsyni n. gen. et sp. and P. incertus n. gen. et sp. from Late Cretaceous Grassy Lake amber, Alberta, Canada. A. P. rasnitsyni holotype oblique ventral habitus diagram with vein nomenclature to upper left of main diagram, TMP 96.6.192a (trailing specimen). Specimen strongly affected by thin-cuticle deformation, with shearing in meso- and metatibiae, and head moderately compressed; B. P. incertus holotype oblique lateral habitus diagram with forewing venation to lower left of main diagram, TMP 96.6.192b (leading specimen). Specimen with eyes, meso- and metathoracic legs, and propodeal sculpture strongly compressed, and possibly distorted. Scale bars $0.75 \mathrm{~mm}(\mathrm{~A}), 0.5 \mathrm{~mm}$ (B).

length and laterally compressed; antennae with dense coat of short, inclined setae, setae slightly longer adjacent to apex of each flagellar article, especially articles VIII to XI; mandibles largely obscured, apparently with single apical tooth and limited taper toward apex; maxillary palps elongate, apparently with four or more seg- ments and sparse, elongate setae. Mesosoma observations limited by low relief of features, dark coloration, and thin-cuticle deformation within region; mesosoma relatively short (dorsoventrally) and elongate, with dense patches of moderately long, inclined setae present on mesoscutum and propodeum; mesoscutum and 
mesoscutellum with low dorsal convexity and weakly differentiated by transcutellar furrow; metanotum not dorsally prominent; propodeum with relatively flat dorsal surface and weak transverse carina present at transition into its posterior declivity. Legs taphonomically distorted, apparently with well defined trochantelli and slightly expanded femora; metatibia expanded distally; in all tarsi, tarsomere I longest, with II and V approximately half length of I, and with III and IV progressively shortening, approaching half of length of $\mathrm{V}$; prominent setation on legs consists of single row of elongate setae sparse on ventral margin of profemur (Fig. 1C), and dense patch of mid-length, inclined setae along dorsal surface of metatibia. Forewing with uniform and relatively dense microtrichial vestiture, and fringe of fine marginal setae slightly longer along apical and posterior subapical regions of wing; venation as figured (Figs 1A, B, 2A) and described in diagnoses. Hind wing small and oar-shaped with marginal setae along apex and posterior margin displaying lengths almost equal to one half width of wing. Metasoma highly distorted in type specimen; long setae inclined and relatively dense on terga, less pronounced on sterna, with lengths and density increasing on posterior metasomal segments; details of genitalia obscured in type specimen due to setae and decay products concentrated near apex of metasoma.

Measurements in mm: Body length 1.41; mesosoma length 0.52 ; metasoma length 0.68 ; antenna length 1.05 ; forewing length 1.28 , hind wing length 0.96 .

\section{Pareubaeus incertus McKellar, Kopylov \& Engel, n. sp.}

Figures 1D-H, 2B

Derivation of name. The specific epithet incertus is a Latin term for "doubtful or unsettled". The name refers to the difficulty in distinguishing the holotype from that of $P$. rasnitsyni.

Holotype. TMP 96.9.192b (leading specimen within amber piece), imago, male. Well preserved, but sculpture details not visible due to thin cuticle deformation. Grassy Lake amber, Foremost Formation, Campanian in age.

Additional material. TMP 96.9 .787 (Fig. 1I) is probably an additional representative of the species, but is not included in the type series for $P$. incertus due to incomplete preservation.

Diagnosis. Antennal length equals 0.63 of total body length; flagellar articles gradually shortening from base to apex, with article II as long as article I, and article $\mathrm{X}$ approximately 0.7 times as long as article I; flagellar article XI nearly cylindrical, 0.9 times as long as article I, and not wider than preceding articles. Mesopleuron comparatively short, 0.36 of mesosomatic length; propodeum comparatively short (anteroposteriorly). Forewing with anterior margin of pterostigma anteriorly-convex; bulla in $2 \mathrm{Rs}+\mathrm{M}$ close to r-rs contact; length of $3 \mathrm{Rs}+\mathrm{M}$ greater than vein's thickness; $1 \mathrm{Rs} \& 1 \mathrm{M}$ nearly straight; $4 \mathrm{Cu}$ nearly straight apical to 2cu-a. Metasoma slender, with first segment short and projecting dorsally; all other metasomal segments subequal in size; metasoma apparently close to cylindrical in outline. P. incertus differs from P. rasnitsyni in having shorter antennae with nearly cylindrical apical flagellar article, and with articles I, II and XI nearly identical lengths. It also differs in metasomal shape, apparent differ- ences in metasomal segmentation (that could possibly be a result of taphonomic distortion), and in its smaller total body size.

Description. As for P. rasnitsyni, except for diagnostic characters and details below: scape apparently inflated, broader than pedicel; moderately long setae inclined on clypeus, as well as erect in single row ventral to each torulus, and erect on genae adjacent to mandibular bases. Mesosoma apparently taller (dorsoventrally) adjacent to mesopleuron than in P. rasnitsyni, but uncertain due to taphonomic distortion; mesoscutum apparently flat dorsally; mesoscutellum with moderate dorsal convexity; metanotum projects dorsally as small crescentic ledge, posterior surface short (dorsoventrally) but nearly overhanging propodeum; propodeal declivity strong; setae suberect on ventral surface of profemur shorter and more numerous. Metasoma apparently with more even segment lengths and widths, with setae in reduced numbers and lengths near posterior apex; apex of metasoma distorted, but perhaps with part of male genitalia exposed (Fig. 1H).

Measurements in mm: Body length 1.22; mesosoma length 0.43 ; metasoma length 0.61 ; antenna length 0.77 ; forewing length 1.08 .

Remarks. Although it is tempting to place both P. rasnitsyni and P. incertus specimens into the same species due to their overall similarity, occurrence as syninclusions, and the possible influence of taphonomic distortion, the differences between the specimens are not possible to explain as a result of taphonomic distortion alone. A third specimen that is probably attributable to P. incertus (TMP 96.9.787, treated as additional material herein) provides some insight into the undistorted morphology of the species, but cannot be confidently placed within the type series of P. incertus because its wings are only preserved basal to the pterostigma.

Subfamily Labeninae Ashmead, 1900 [Labiinae of Townes, 1969]

Tribe Poecilocryptini Townes \& Townes, 1960

\section{Genus Albertocryptus McKellar, Kopylov, \& Engel, n. gen.}

Derivation of name. The genus name is a combination of "alberto" and "cryptus", referring to both the discovery site (Alberta) and similarities to the extant genus Poecilocryptus Cameron, 1901. The name is masculine and Latin.

Type species. Albertocryptus dossenus n. sp.

Diagnosis. Antennae with 17 flagellar articles, threadlike; compound eyes with inner margins parallel ventrally; mandibles apparently thin with two stout teeth; notauli well-impressed, converging posteriorly, and fading anterior to mid-length of pronotum; protibia with one curved spur, meso- and metatibiae with paired straight spurs; pretarsal claws smooth; forewing length $1.9 \mathrm{~mm}$; forewing with large pterostigma; areolet pentagonal, with rs-m longer than $2 \mathrm{Rs}$ and $2+3 \mathrm{M}$ longer than $4 \mathrm{M} ; 1 \mathrm{~m}$-cu\&2Rs $+\mathrm{M}$ sharply angled at $1 \mathrm{~m}$-cu and $2 \mathrm{Rs}+\mathrm{M}$ junction, with bulla encompassing basal half of $2 \mathrm{Rs}+\mathrm{M}$, and with ramulus absent; $2 \mathrm{~m}$-cu with 2 distinct bullae; $1 \mathrm{cu}-\mathrm{a}$ postfurcal; hind 
wing with four hook-shaped distal hamuli, rs-m longer than 1Rs, rs-m with bulla, 2Rs short, $2 \mathrm{M}$ absent, $\mathrm{M}+\mathrm{Cu}$ arched, and nervellus (1Cu\&cu-a) not intercepted; propodeum with strong carinae; metasoma attached low on propodeum, but dorsal to metacoxal bases; first metasomal segment long and slender anteriorly and widened posteriorly, with spiracle behind its mid-length; metasoma slender and cylindrical. Albertocryptus differs from all other poecilocryptine genera in possessing larger pterostigma and smaller body size; it is similar to Poecilocryptus Cameron, 1901 in forewing venation (large pterostig$\mathrm{ma}$, areolet size, $1 \mathrm{~m}$-cu\&2Rs $+\mathrm{M}$ shape, nervellus not intercepted), propodeal areolation and shape of first metasomal segment, but differs in its lower number of antennal segments, having two bullae in $2 \mathrm{~m}$-cu, having 1cu-a postfurcal in the forewing, having shorter vein $2 \mathrm{Rs}$, and in lacking vein $2 \mathrm{M}$ in hind wing.

Species composition. Albertocryptus dossenus n. sp., from Late Cretaceous (Campanian) amber of western Canada.

Remarks. The new genus has a rather long and slender first metasomal segment, and its spiracle is positioned behind the mid-length of the tergite. This metasomal shape is the most common among modern ichneumonids but it is unique among Cretaceous exemplars.

The genus is placed into subfamily Labeninae because it displays: a metasomal articulation that is dorsal to the metacoxal bases; a combination of a large pentagonal areolet in the forewing, and a short $1 \mathrm{Rs}$ in hindwing; and because of the shape of its first metasomal segment. Albertocryptus is highly similar to some Ichneumoninae and Cryptinae, but differs in the 1Rs/rs$\mathrm{m}$ ratio found in the hindwing (the above-mentioned subfamilies have 1Rs longer than rs-m). Albertocryptus also displays a smaller size and larger areolet in the forewing (compared to most genera). The new genus has wing venation close to that of some Pimplinae, Tryphoninae, and Labenopimplinae, but it differs in the shape of its first metasomal segment.

The new genus is placed into tribe Poecilocryptini (Brachycyrtini sensu Townes 1969) tentatively. In the future, it may be worthwhile suggesting a new tribe, or, possibly, even a new subfamily, but stating a new highrank taxon based on only two male specimens seems rather groundless. We prefer to suspend this problem until Late Cretaceous Ichneumonidae are better represented. At present, noteworthy differences include the possession of a second bulla within the $2 \mathrm{~m}-\mathrm{cu}$ crossvein in the new genus. This suggests that the fossil material lacks at least one of the eight synapomorphies proposed by Gauld \& Wahl (2000) for Poecilocryptini. Of the three genera in Poecilocryptini, the fossil specimens most closely resemble the Australian genus Poecilocryptus. The superficial similarity to Poecilocryptus is strong enough that the fossil specimens key to this genus in the works of Wahl (1996) and Gauld \& Wahl (2000).

\section{Albertocryptus dossenus McKellar, Kopylov \& Engel, n. sp. \\ Figures $3 \mathrm{~A}-\mathrm{H}, 4 \mathrm{~A}-\mathrm{C}$}

Derivation of name. The specific epithet dossenus is Latin for "humpback" and refers to the dorsally prominent mesoscutellum observed within the species. It is to be treated as a noun in apposition.
Holotype. TMP 96.9.186, imago, male. Specimen well preserved except for missing tarsi and antennal bases partly obscured by dark drying line within amber. Grassy Lake amber, Foremost Formation, Campanian in age.

Additional material. P1602, imago, male. Specimen complete except for wing apices, largely concealed by dark drying line, and only visible in oblique view. Grassy Lake amber, Foremost Formation, Campanian.

Diagnosis. As for genus, by monotypy (vide supra)

Description. Head tall and foreshortened, apparently with concave frons and prominent ocelli; sunken frons and face may be result of taphonomic distortion (P1602 displays gently convex frons and face situated between prominent compound eyes); vertex broadly rounded, grading gently into occiput; no occipital carina visible; ocelli closely spaced and dorsally prominent; compound eye tall ( 0.66 of total cephalic height), encompassing much of anterolateral surface of head, and obscuring face in lateral view; antenna length equal to 0.6 of total body length, with long scape; pedicel short, inflated ('comma-shaped') and enveloping anterior surface of first flagellar article; scape and pedicel with few, moderately long, suberect setae; flagellum threadlike, basal flagellar articles cylindrical and 4 times as long as wide, subapical ones $\sim 1.2$ times so; flagellar articles all with dense coat of short setae which are coarser and inclined on dorsal surface, and slightly finer and inclined in various orientations on ventral surface, and apex of each flagellar article with circlet of erect, moderately long setae; face (Fig. 4B) gently convex ventral to toruli, and with short, convex clypeus separated from face by furrow in P1602 (but not clearly visible in type specimen); gena tall and narrow (anteroposteriorly); labrum elongate with low convexity, projecting above mandibles and bearing few, short, inclined setae; left mandible uniformly narrow along its entire length, with two short and broad apical teeth, and slightly overlapping right mandible; maxillary palp long and four-segmented, with row of erect setae along anterior margin and inclined setae along posterior margin, with setae lengths equal to width of each palpal segment; labial palpus apparently with three short, subequal segments bearing sparse elongate setae (difficult to observe).

Mesosoma 0.37 of total body length; mesoscutum shagreened and apparently glabrous, with low dorsal convexity, and deeply concave adjacent to mesoscutellum; mesoscutellum dorsally-prominent, comprising nearly one-quarter of total height of mesosoma, with anterodorsal extreme drawn into broadly rounded point and flanked by prominent, sharp carinae laterally; mesoscutellum with very short, sparse, inclined setae; metanotum broad and pyramidal in shape, recessed with respect to mesoscutellum and propodeum; propodeum marked by prominent carinae, with basal area and areola short (anteroposteriorly) and petiolar area long (comprising about 0.75 of propodeal length); coarse stiff setae or spines present in transverse row along apical transverse carina, with spines positioned at junctions with lateral longitudinal carina, and with spine lengths 


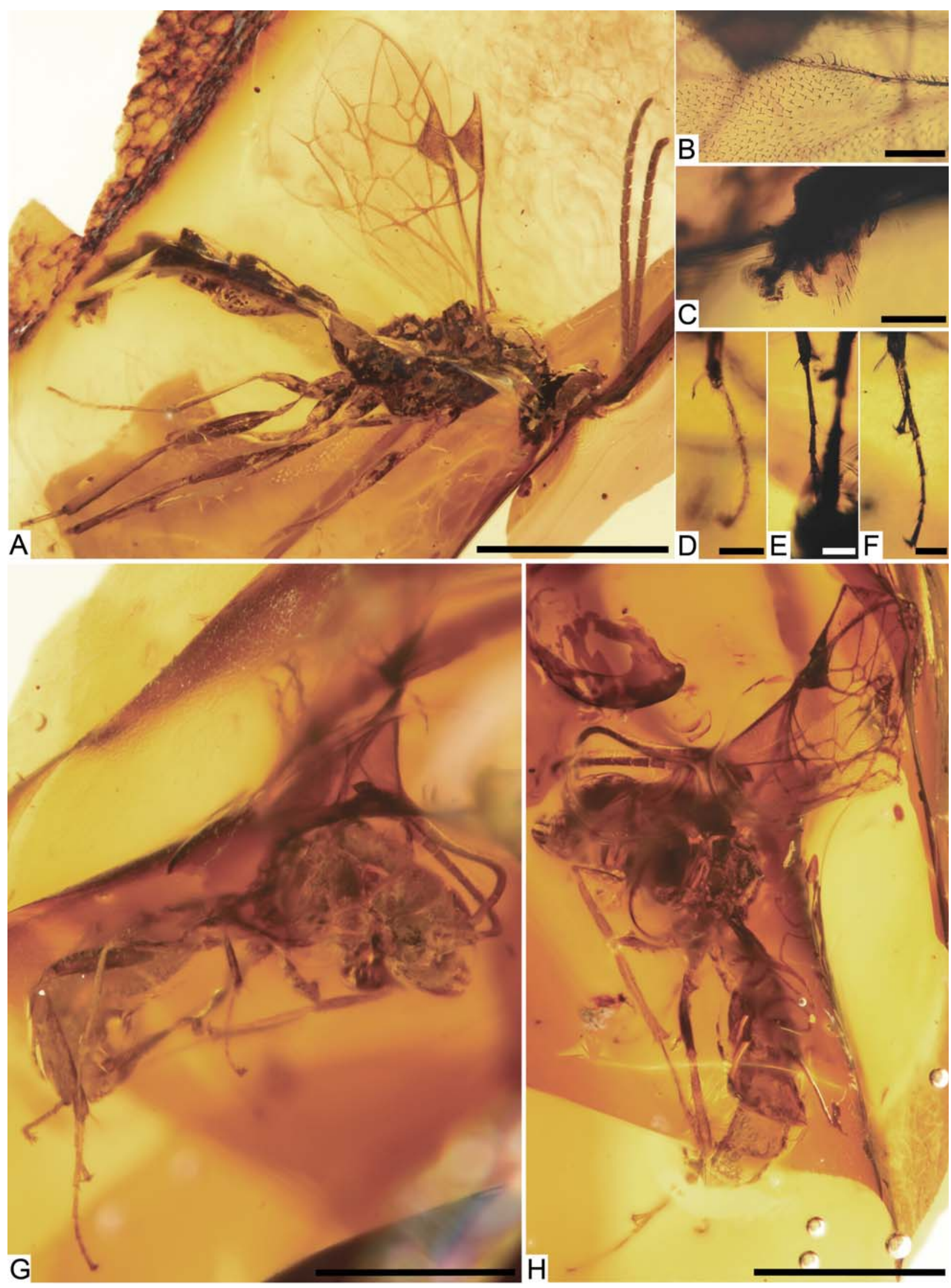

Figure 3. Albertocryptus dossenus n. gen. et sp. from Late Cretaceous Grassy Lake amber, Alberta, Canada. A-C. Holotype male, TMP 96.9.186; A. Lateral view; B. Details of hamuli (bright field photomicrographs); C. Details of metasomal apex (bright field photomicrographs); D-H. Probable conspecific male, TMP 96.9.787; D. Protibial spur and protarsus; E. Mesotibial spurs and partial view of mesotarsus; F. Metatibial spurs and metatarsus; G. Oblique anteroventral view; H. Oblique posterodorsal view. Scale bars $1 \mathrm{~mm}(\mathrm{~A}, \mathrm{G}, \mathrm{H}), 0.1 \mathrm{~mm}(\mathrm{~B}-\mathrm{F})$. 


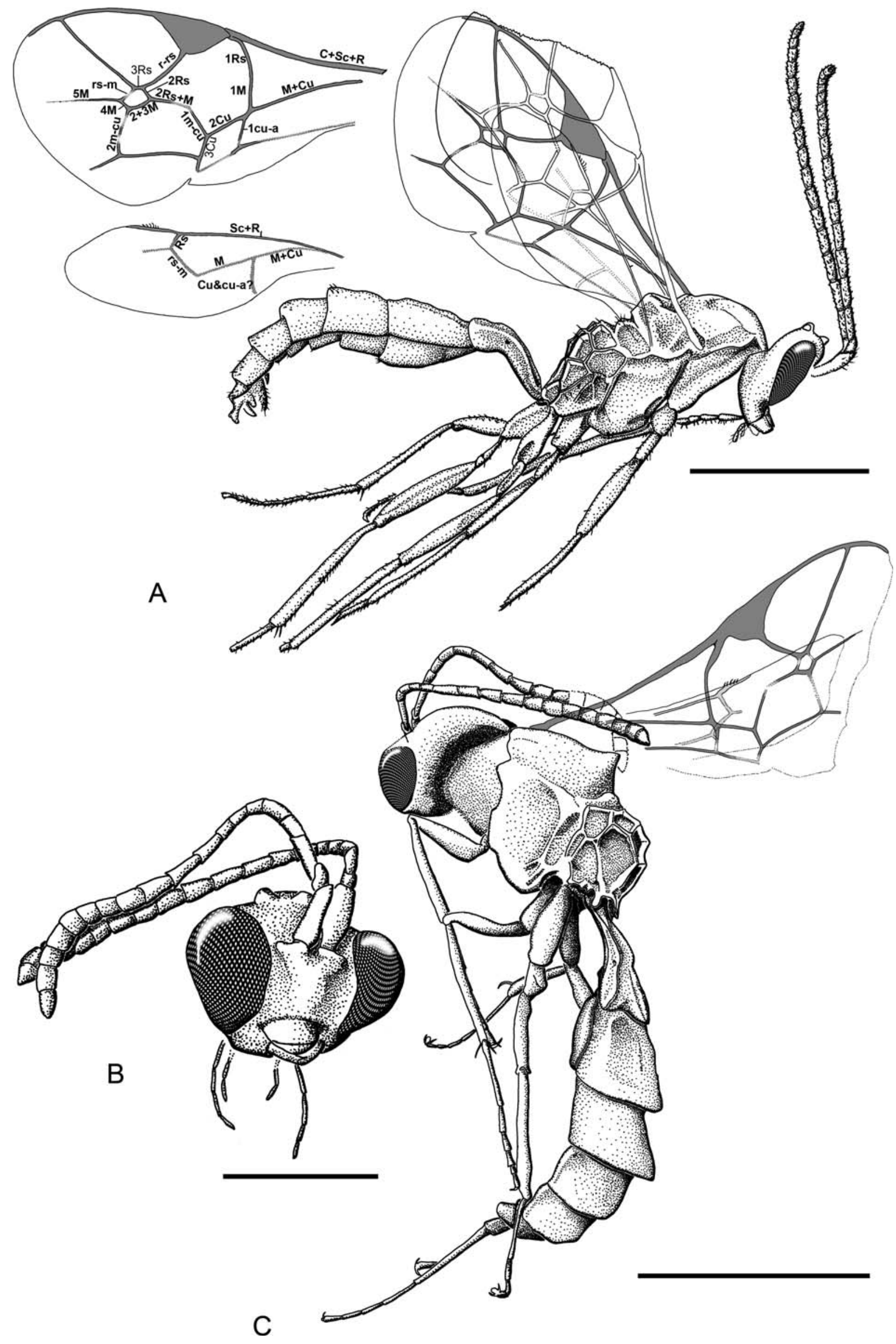


equal to height of carinae; propodeal carinae bear small number of fine erect setae in addition to spines; metasomal articulation positioned low, within one coxal width of metacoxa. Forewing with rs-m spectral; $2 \mathrm{~m}$-cu slightly sinuous; $2 \mathrm{Rs}+\mathrm{M}$ with bulla in its basal third; $2 \mathrm{R}$ extending beyond junction with $4 \mathrm{Rs}$, with length equal to that of areolet. Hind wing apparently with four curved distal hamuli plus two straight hamuli at proximal end of row; single, straight basal hamulus present.

Procoxa short and somewhat bulbous; meso- and metacoxa positioned close to one another; pro- and mesofemur slightly swollen within apical two-thirds of their length, with metafemur slightly compressed and incrassate; all tibiae expanded slightly at apex; procoxa, profemur and protibia all with sparse coat of short inclined setae concentrated on dorsal surface, with setation pattern similar in subsequent legs; protibia apparently with single long, curved, apical spur that is roughly 1.5 times as long as maximum tibial width (spur poorly preserved); all tarsomeres with moderately dense arrangement of inclined, thick setae, with setae becoming more numerous on ventral surface and toward apex of each tarsomere; pretarsal claws simple and stout, and arolium well developed; mesotibia with two apical spurs, one straight and 1.5 times as long as apical width of tibia, and one small and straight, barely discernible; metatibia with pair of straight apical spurs, each 1.5-2 times as long as tibia is wide; apical twothirds of metatibia with double row of stiff setae or spicules inclined on ventral surface.

Metasoma with first segment longest and second segment 0.8 times as long as first, very wide; third segment 0.5 times as long as first; tergite I with prominent dorsolateral carina, and spiracle located beneath carina, with spiracle positioned at approximately 0.56 of tergite's length; metasoma with few, sparse, short, inclined setae concentrated toward posterior margin of each tergite, with tergites IV-VI bearing setae in a more dense arrangement.

Measurements (in $\mathrm{mm}$ ): Total body length 2.9; head height 0.52 , length 0.27 ; antenna length 1.75 ; mesosoma length 1.08 , height 0.63 ; forewing length 1.9 , width 0.94 ; hind wing length 1.32 ; metasoma length 1.68 .

Figure 4. Albertocryptus dossenus n. gen. et sp. from Late Cretaceous Grassy Lake amber, Alberta, Canada. A. Holotype male, TMP 96.6.192, lateral habitus diagram. Portions of wing apices, one antennal apex, and much of the tarsi are not preserved; curvature of antennal apices obscures segmentation (19-segmented antennae barely visible on left side); details of the frons and metasomal posterior apex are partly obscured by interaction with drying lines and bubble-clouding, left hind wing and microtrichial vestiture omitted for clarity; B, C. Specimen P1602, additional material, anterior view of head and dorsolateral habitus diagram, respectively. Specimen visibility impaired by thickness of surrounding amber, and interaction of dorsal surface with dark drying line; setae omitted. Scale bars $0.5 \mathrm{~mm}$ (A, B), $1.0 \mathrm{~mm}$ (C).
Remarks. A single additional specimen (P1602) is not included within the type series for $A$. dossenus. Even though preservation is relatively good in P1602, many details are obscured by a dark drying line within the encapsulating amber and contortion of the specimen, and most observations obtained from oblique views. Specimen P1602 is very similar to the holotype, yet it is unclear whether small distinctions (such as an areolet that appears smaller than that of the type specimen) warrant the recognition of a second species or are simply a result of the viewing angle. It is hoped that additional material will clarify the position of P1602 with respect to the type specimen.

\section{Discussion}

The Late Cretaceous ichneumonid taxa recovered from Canadian amber match well with the expectations generated by both recent phylogenetic studies, and the broader fossil record of Ichneumonidae. Labenopimplinae, such as the Pareubaeus species described herein, have already been suggested to be the predominant Late Cretaceous group of ichneumonids - replacing the subfamilies Palaeoichneumoninae Kopylov, 2009 and Tanychorinae Rasnitsyn, 1975 that disappeared at the end of the Early Cretaceous (Kopylov et al. 2010). While this appears on the surface intuitively pleasing, none of the phylogenetic studies have tested the monophyly of these extinct subfamilies and at least Tanychorinae is dubious as it is based solely on plesiomorphies. Accordingly, this purported turnover may simply be an artifact of a non-phylogenetic classification rather than any shift in the composition of ichneumonid faunas. Clearly, significant cladistic work is needed to clarify the relationships among Mesozoic ichneumonoids and relative to their modern counterparts.

The present study provides the first Cretaceous record of Labeninae, but the subfamily has been proposed as either the basalmost among extant ichneumonids, using morphological data (Gauld 1983; Wahl 1993), or merely near the base of the family using molecular data (e.g., Quicke et al. 1999). If ichneumonids were not unknown from most other Cretaceous amber deposits, the families represented in Canadian amber would likely be considered unremarkable.

The fact that definitive ichneumonids are present in Late Cretaceous Canadian and Siberian amber, yet apparently absent from major Early Cretaceous deposits in Lebanon, Spain, and France could indicate a number of different things. Their presence or absence could simply be an artifact of sampling: Canadian and Siberian amber deposits are both represented by more than 3000 inclusions, while most other Cretaceous deposits have significantly smaller sample sizes (vide Perrichot et al. 2008, tab. 1). Alternatively, Canadian and Siberian amber are the youngest and northernmost of the Cretaceous deposits with a high diversity of inclusions (Martínez-Delclòs et al. 2004; Grimaldi \& Engel 2005): the 
taxa may not exist in the other regions or time intervals sampled.

The temporal range of the groups involved can be discounted as a potential explanation for their occurrence records, because Labenopimplinae have previously been recovered as compression fossils in the Cenomanian Ola Formation of the Russian Far East (Kopylov 2010b). (Although geographically removed, this deposit was formed well before the more proximal, Turonian amber of New Jersey). Alternatively, latitude effects on host availability have been suggested as a control on the geographic distribution of modern ichneumonids (e.g., Sime \& Brower 1998, and references therein), and may well have influenced their paleobiogeography too. Paleolatitude has been suggested as an explanation for the abundance of Coccoidea (scale insects) in New Jersey amber, while the Canadian and Siberian deposits contain Aphidoidea (aphids) as the predominant herbivorous insects (Grimaldi et al. 2000). This distinction has supported the interpretation of New Jersey amber as representing a warm-temperate or subtropical environment, while the Canadian and Siberian deposits are more temperate in character (Grimaldi et al. 2000). The new ichneumonids from Canadian amber add further support to the paleolatitude hypothesis, demonstrating that species closely related to Eubaeus were also present in the western part of Laurentia. The growing list of close relatives and genera shared between these two deposits now includes common Cretaceous hymenopterans such as Serphites Brues, 1937 and rarer taxa, such as Conostigmus Dahlbom, 1858 (Megaspilidae) and Celonophamia Evans, 1973 (Bethylidae) (McKellar \& Engel 2012). Coupled with the general similarities between which families are present in the two deposits, and their relative abundances (Zherikhin \& Sukatsheva 1973; McKellar \& Engel 2012), there appears to be a much stronger correspondence between these two deposits than there is between either deposit and New Jersey amber. More taxa will have to be examined in detail (and across a range of amber deposits) in order to draw any conclusions regarding the influence of paleolatitude, but the existing data hint at a potential role in the distribution and regional diversity of groups such as Ichneumonidae.

In terms of temporal ranges, the Canadian amber assemblage demonstrates that Labenopimplinae persisted until at least the Campanian before vanishing from the fossil record. This must be considered with caution, however, as labenopimpline paraphyly could indicate the subfamily as merely a stem lineage to an as of yet surviving subfamily. Cladistic tests are needed to clarify which scenario is most rigorously supported. Regardless, the Canadian amber assemblage also adds an interesting twist to the palaeobiogeographic story of Labeninae. Gauld \& Wahl (2000) documented the predominantly Gondwanan distribution of modern Labeninae and concluded that the subfamily most likely originated somewhere in the southern continents, prior to the breakup of Gondwana. In this scenario, the few modern North American taxa represent the result of a relatively recent colonization event. The Canadian amber specimens do not undermine this hypothesis. Instead, they extend the fossil record of the subfamily closer to the proposed time of origination, and also demonstrate that at least one of the basal labenine taxa may have been relatively widespread by the end of the Cretaceous period. As with many modern insects that have a predominantly austral modern distribution, basal Labeninae appear to have been extirpated from Laurentia as a result of Tertiary climate change (Grimaldi \& Engel 2005), but have partially re-colonized the region.

\section{Acknowledgements}

This paper is dedicated warmly to Alexandr P. Rasnitsyn. Dr. Rasnitsyn has made a truly exceptional contribution to the study of fossil Hymenoptera, and we wish him many more years of active research. We thank Michael Ohl and Jaime Ortega-Blanco for their constructive reviews of this work. Additionally, we thank Brandon Strilisky and Jim Gardner for their assistance with the TMP collections, and Andrew Locock for assistance with the P collection. The Leuck family generously donated specimen P1602 and provided field assistance. Support was provided by a Natural Sciences and Engineering Research Council of Canada Postdoctoral Fellowship (to R.C.M.), Russian Foundation for Basic Research grant 12-04-01177-a and the Program "Origin of the Biosphere and Evolution of Geobiological Systems" of the Presidium of the Russian Academy of Sciences (to D.S.K.), and U.S. National Science Foundation grants EF-0341724 and DEB-0542909 (to M.S.E.), as well as NSERC Discovery grants issued to B.D.E. Chatterton and A.P. Wolfe, University of Alberta.

\section{References}

Ashmead, W. H. 1900. Order Hymenoptera. In Smith J. B. (ed.). Insects of New Jersey, a list of species occurring in New Jersey, with notes on those of economic importance. MacCrellish \& Quigley, Trenton: pp. 501-614.

Azar, D., Gèze, R. \& Acra, F. 2010. Lebanese amber. In Penney D. (ed.). Biodiversity of fossils in amber from the major world deposits. Siri Scientific Press, Manchester: pp. 271-298.

Brues, C. T. 1937. Superfamilies Ichneumonoidea, Serphoidea, and Chalcidoidea. In Carpenter, F. M., Folsom, J. W., Essig, E. O., Kinsey, A. C., Brues, C. T., Boesel, M. W. \& Ewing, H. E. (eds) Insects and Arachnids from Canadian amber. - University of Toronto Studies, Geological Series 40: 27-44.

Cameron, P. 1901. Descriptions of seventeen new genera of Ichneumonidae from India and one from Australia. - Annals and Magazine of Natural History 7 (7): 423-551.

Dahlbom, A. G. 1858. Svenska Små-Ichneumononernas familjer och slägten. - Öfversigt Af Kongliga Ventenskaps-Akadamiens Förhandlingar 14: 289-298 [In Swedish]

Engel, M. S. \& Krombein, K. V. 2012. Hymenoptera. In McGraw-Hill Encyclopedia of Science and Technology [11th Edition, Volume 8] McGraw-Hill, New York: pp. 787-798.

Evans, H. E. 1973. Cretaceous aculeate wasps from Taimyr, Siberia (Hymenoptera). - Psyche 80: 166-178.

Gauld, I. D. 1983. The classification, evolution and distribution of the Labeninae, an ancient southern group of Ichneumonidae (Hymenoptera). - Systematic Entomology 8: 167-178.

Gauld, I. D. \& Bolton, B. 1988. The Hymenoptera. Oxford University Press, Oxford. 
Gauld, I. D. \& Wahl, D. B. 2000. The Labeninae (Hymenoptera: Ichneumonidae): a study in phylogenetic reconstruction and evolutionary biology. - Zoological Journal of the Linnean Society 129: 271-347.

Grimaldi, D. \& Engel, M. S. 2005. Evolution of the Insects. Cambridge University Press, Cambridge.

Grimaldi, D. A., Shedrinsky, A. \& Wampler, T. P. 2000. A remarkable deposit of fossiliferous amber from the Upper Cretaceous (Turonian) of New Jersey. In Grimaldi, D. A. (ed.). Studies on fossils in amber, with particular reference to the Cretaceous of New Jersey. Backhuys Publishers, Leiden: pp. 1-76.

Huber, J. T. 2009. Biodiversity of Hymenoptera. In Foottit, R. \& Adler, P. (eds). Insect Biodiversity: Science and Society. WileyBlackwell, Oxford: pp. 303-323.

Huber, J. T. \& Sharkey, M. J. 1993. Structure. In Goulet, H. \& Huber, J. T. (eds). Hymenoptera of the World: an identification Guide to Families. Agriculture Canada Research Branch Monograph 1894/ E, Ottawa: pp. 13-59.

Kopylov, D. S. 2009. A New Subfamily of Ichneumonids from the Lower Cretaceous of Transbaikalia and Mongolia (Insecta: Hymenoptera: Ichneumonidae). - Paleontologicheskii Zhurnal 1: 7685. [In Russian, reprinted in English, 2009, Paleontological Journal, 43 (1): 83-93.]

Kopylov, D. S. 2010a. Ichneumonids of the Subfamily Tanychorinae (Insecta: Hymenoptera: Ichneumonidae) from the Lower Cretaceous of Transbaikalia and Mongolia. - Paleontologicheskii Zhurnal 2: 57-63. [In Russian, reprinted in English, 2010, Paleontological Journal, 44 (2): 180-18.]

Kopylov, D. S. 2010b. A New Subfamily of Ichneumon Wasps (Insecta: Hymenoptera: Ichneumonidae) from the Upper Cretaceous of the Russian Far East. - Paleontologicheskii Zhurnal, 4: 59-69. [In Russian, reprinted in English, 2010, Paleontological Journal, 44 (4): 422-433].

Kopylov, D. S., Brothers, D. J. \& Rasnitsyn, A. P. 2010. Two new labenopimpline ichneumonids (Hymenoptera: Ichneumonidae) from the Upper Cretaceous of Southern Africa. - African Invertebrates 51 (2): 423-430.

Kopylov, D. S. 2012. New Ichneumonidae (Hymenoptera) from the Upper Cretaceous ambers of the Taimyr Penninsula. - Paleontologicheskii Zhurnal, 4: 52-59. [In Russian, reprinted in English, 2012, Paleontological Journal, 46 (4): 383-391.]

Latreille, P. A. 1802. Histoire naturelle, générale et particulière, des Crustacés et des Insectes, Tome troisieme. Paris.

Martínez-Delclòs, X., Briggs, D. E. G. \& Peñalver, E. 2004. Taphonomy of insects in carbonates and amber. - Palaeogeography, Palaeoclimatology, Palaeoecology 203: 19-64.

McKellar, R. C., Wolfe, A. P., Tappert, R. \& Muehlenbachs, K. 2008. Correlation of Grassy Lake and Cedar Lake ambers using infrared spectroscopy, stable isotopes, and palaeoentomology. - Canadian Journal of Earth Sciences 45: 1061-1082.

McKellar, R. C. \& Engel, M. S. 2012. Hymenoptera in Canadian Cretaceous amber (Insecta). - Cretaceous Research 35: 258-279.

Nascimbene, P. \& Silverstein, H. 2000. The preparation of fragile Cretaceous ambers for conservation and study of organismal inclusions. In Grimaldi, D. A. (ed.). Studies on fossils in amber, with particular reference to the Cretaceous of New Jersey. Backhuys Publishers, Leiden: pp. 93-102.

Peñalver, E. \& Delclòs, X. 2010. Spanish amber. In Penney D. (ed.). Biodiversity of fossils in amber from the major world deposits. Siri Scientific Press, Manchester: pp. 236-270.
Perrichot, V., Lacau, S., Néraudeau, D. \& Nel, A. 2008. Fossil evidence for early ant evolution. - Naturwissenschaften 95: 85-90.

Perrichot, V., Néraudeau, D. \& Tafforeau, P. 2010. Charentese amber. In Penney D. (ed.). Biodiversity of fossils in amber from the major world deposits. Siri Scientific Press, Manchester: pp. 190207.

Pike, E. M. 1995. Amber taphonomy and the Grassy Lake, Alberta amber fauna. Ph.D. Thesis. Department of Biological Sciences, University of Calgary, Alberta.

Quicke, D. L. J., Lopez-Vaamonde, C. \& Belshaw, R. 1999. The basal Ichneumonidae (Insecta, Hymenoptera): 28S D2 rDNA considerations of the Brachycyrtinae, Labeninae, Paxylommatinae and Xoridinae. - Zoologica Scripta 28 (1-2): 203-210.

Rasnitsyn, A. P. 1975. Hymenoptera Apocrita of the Mesozoic. Transactions of the Paleontological Institute of the USSR Academy of Sciences [Trudy Paleontologicheskogo instituta Akademii nauk SSSR] 147: 1-134. [In Russian].

Ross, A., Mellish, C., York, P. \& Crighton, B. 2010. Burmese amber. In Penney D. (ed.). Biodiversity of fossils in amber from the major world deposits. Siri Scientific Press, Manchester: pp. 208235 .

Sime, K. R. \& Brower, A. V. Z. 1998. Explaining the latitudinal gradient anomaly in ichneumonid species richness: evidence from butterflies. - Journal of Animal Ecology 67: 387-399.

Skidmore, R. E. 1999. Checklist of Canadian amber inclusions in the Canadian National Collection of Insects. Research Branch Agriculture and Agri-Food Canada electronic publication. Available from www.biology.ualberta.ca/facilities/strickland/SKIDMORECNCCanadianAmberInclusions.pdf [cited 22 September, 2012].

Townes, H. 1969. The Genera of Ichneumonidae, Part 1. - Memoirs of the American Entomological Institute 11: 1-300.

Townes, H. 1973a. Two ichneumonids (Hymenoptera) from the Early Cretaceous. - Proceedings of the Entomological Society of Washington 75 (2): 216-219.

Townes, H. 1973b. Three Tryphoninae ichneumonids from Cretaceous amber (Hymenoptera). - Proceedings of the Entomological Society of Washington 75 (3): 282-287.

Townes, H. K., Townes, M., Walley, G. S. \& Townes, G. 1960. Ichneumon-flies of American north of Mexico: 2 Subfamily Ephialtinae, Xoridinae, Acaenitinae. - United States National Museum Bulletin 216 (2): 1-676.

Wahl, D. B. 1993. Cladistics of the ichneumonid subfamily Labeninae (Hymenoptera: Ichneumonidae). - Entomologia Generalis 18: $91-105$.

Wahl, D. B. 1996. Xenothyrini, a new tribe of Labeninae, and a key to the tribes and genera of Labeninae (Hymenoptera: Ichneumonidae). - Proceedings of the Entomological Society of Washington 98 (1): $158-161$.

Wahl, D. B. \& Sharkey, M. J. 1993. Superfamily Ichneumonoidea. In Goulet, H. \& Huber, J. T. (eds). Hymenoptera of the World: an identification Guide to Families. - Agriculture Canada Research Branch Monograph 1894/E, Ottawa: pp. 358-509.

Yu, D. S.; Van Achterberg, K; Horstmann, K. 2005. World Ichneumonoidea 2004. Taxonomy, biology, morphology and distribution. Taxapad 2005. CD/DVD. Taxapad, Vancouver, www.taxapad.com.

Zherikhin, V. V. \& Sukatsheva, I. D. 1973. On the Cretaceous insectbearing "ambers" (retinites) from North Siberia. In Narchuk, E. P. (ed.). Problems in Insect Palaeontology: XXIV Annual Lectures in Memory of N. A. Kholodovsky (1-2 April 1971). Nauka Press, Leningrad, pp. 3-48. [In Russian]. 